\title{
KEPEMIMPINAN TRANSFORMATIF DALAM PERSPEKTIF PENDIDIKAN AGAMA KRISTEN
}

\author{
HARUN Y. NATONIS \\ SEKOLAH TINGGI AGAMA KRISTEN NEGERI KUPANG
}

harunnatonis@gmail.com

\begin{abstract}
The purpose of this research article is to find out 1). Transformative leadership from the perspective of Christian Religious Education ; 2). Characteristics of transformative leadership in the perspective of Christian Religious Education; 3). Strategies in implementing transformative leadership in the perspective of Christian Religious Education. The method in this research is qualitative. The techniques used in collecting data are observation, in-depth interviews and document study.

Then the results obtained in this study are 1). In the perspective of Christian Religious Education, transformative leadership is seen in the leadership character of Jesus. 2). Jesus' transformative leadership shows that in leadership, a leader must be authoritative. 3). With authority, the leader runs the leadership with careful planning and strategy. A mature strategy helps leaders and their communities solve problems. This leader has the competence to know the character of each individual they lead. Leaders are also able to look at the future of their communities and want their communities to develop independently. And the most important of these leaders are leaders who are able to be role models for their people.
\end{abstract}

Keywords: transformative leadership, jesus leadership

\begin{abstract}
ABSTRAK
Tujuan dari artikel penelitian ini adalah untuk mengetahui 1). Kepemimpinan transformatif dari perspektif Pendidikan Agama Kristen; 2). Karakteristik kepemimpinan transformatif dalam perspektif Pendidikan Agama Kristen; 3). Strategi dalam mengimplementasikan kepemimpinan transformatif dalam perspektif Pendidikan Agama Kristen. Metode dalam penelitian ini adalah kualitatif. Teknik yang digunakan dalam mengumpulkan data adalah observasi, wawancara mendalam dan studi dokumen.

Maka hasil yang diperoleh pada penelitian ini adalah 1). Dalam perspektif Pendidikan Agama Kristen, kepemimpinan transformatif dilihat dalam karakter kepemimpinan Yesus. 2). Kepemimpinan transformatif Yesus menunjukkan bahwa dalam kepemimpinan, seorang pemimpin harus berwibawa. Dengan kewibawaan, maka pemimpin menjalankan kepemimpinan dengan perencanaan dan strategi yang matang. 3). Strategi yang matang menolong pemimpin dan masyarakatnya menyelesaikan masalah. Pemimpin ini memiliki kompetensi mengetahui karakter setiap individu yang dipimpinnya. Pemimpin juga mampu memandang masa depan masyarakatnya dan menghendaki masyarakatnya dapat berkembang secara mandiri. Dan yang paling utama pemimpin ini adalah pemimpin yang mampu menjadi teladan bagi masyarakatnya.
\end{abstract}

Kata Kunci: kepemimpinan transformatif, kepemimpinan yesus

\section{PENDAHULUAN}

Kepemimpinan merupakan salah satu faktor yang sangat menentukan dalam pengembangan dan kemajuan dari sebuah organisasi. Dengan adanya kepemimpinan yang kapabel akan berdampak bagi kemajuan organsasi. Sebab pemimpin sangat diperlukan untuk menentukan visi dan tujuan organisasi, mengalokasikan dan memotivasi sumberdaya agar lebih kompeten, mengkoordinasikan perubahan, serta membangun pemberdayaan yang intens dengan 
pengikutnya untuk menetapkan arah yang benar atau yang paling baik. Sebagaimana yang dikemukakan oleh Kotler (dalam Lunenburg) menjelaskan bahwa:

"the leadership process involves (a) developing a vision for the organization; (b) aligning people with that vision through communication; and (c) motivating people to action through empowerment and through basic need fulfillment. The leadership process creates uncertainty and change in the organization "."

Berdasarkan definisi diatas, dapat dilihat bahwa kepemimpinan menjadi sangat urgent dalam mengawal kemajuan bagi organisasi dalam kondisi yang seringkali menghadapi perubahan yang tidak menentu. Menurut Lawler mengatakan bahwa perubahan yang tidak menentu ini membutuhkan sorang pemimpin yang mampu mengantisipasi perubahan dengan pengetahuan yang konfrehensif dalam mentrasformasikan perubahan organisasi. Salah satu model kepemimpinan yang tampaknya menjanjikan dalam hal pengelolaan perubahan yang sedang berlangsung dalam organisasi ini adalah model kepemimpinan transformasional berdasarkan visi dan pemberdayaan yang telah menunjukkan efek positif ${ }^{2}$

Maka pada Suatu wilayah maupun organisasi membutuhkan pemimpin. Pemimpin adalah orang yang dipercayakan untuk mengayomi orang-orang dalam wilayah maupun organisasi yang dipimpinnya. Pemimpin biasanya adalah tokoh sentral yang memiliki sikap dan tanggungjawabnya lebih baik sehingga dipercayakan untuk memimpin suatu wilayah maupun organisasi. Krech dan Cruthfield seperti yang dikutip oleh Pamudji mengatakan bahwa "seorang pemimpin memiliki posisi yang istimewa dalam kelompok atau persekutuan yang dipimpinnya, sehingga ia bertindak sebagai sarana dalam penentuan struktur, suasana, tujuan, ideologi dan kegiatan kelompok. ${ }^{3}$

Kebutuhan utama dari suatu masyarakat adalah kesejahteraan. Kesejahteraan masyarakat sangat bergantung dari pola kepemimpinan dari para pemimpinnya. Memang sulit menemukan karakter kepemimpinan yang sempurna dan berhasil dalam kepemimpinannya di tengah-tengah masyarakat.

Pemimpin yang efektif adalah pemimpin yang memiliki daya kepemimpinan yang transformatif. Kepemimpinan yang transformatif menjadikan seorang pemimpin mengarahkan sasaran-sasaran visi dan misi pada masa depan. Pemimpin bergerak dan melangkahkan ke suatu tujuan yang transformastif bagi masa depan orang-orang yang dipimpinnya. ${ }^{4}$

Kepemimpinan transformatif adalah kepemimpinan yang diharapkan oleh seluruh masyarakat, baik dalam ranah pemerintahan, politik, pendidikan, agama, ekonomi, dan sebagainya. Kepemimpinan transformative diidentifikasikan sebagai kepemimpinan dimana para pemimpin menggunakan kharisma mereka untuk melakukan transformasi dan merevitalisasi organisasinya. ${ }^{5}$

Pemimpin yang transformatif biasanya lebih mengutamakan revitalisasi masyarakat dan organisasinya secara integral dari pada memberikan instruksi yang bersifat topdown. Pemimpin yang transformatif selalu menempatkan diri sebagai mentor yang bersedia menampung aspirasi

\footnotetext{
${ }^{1}$ Lunenburg, C. Fred. 2011. Self-Efficacy in the Workplace: Implications for Motivation and Performance. Sam Houstan State University, International Journal of Management, Business, and Administration. Vol. 14.

Number 1, 2011

${ }^{2}$ Lawler, J. 2007. "Leadership in social work: A case of caveat emptor?". British Journal of Social Work, 37, $123-41$

${ }^{3}$ S. Pamudji, Kepemimpinan Pemerintahan di Indonesia, Jakarta: Bina Aksara, 1989, 10.

${ }^{4}$ Bob Moffitt dan Karla Tesch, Andaikan Yesus Kepala Daerah-Tranformasi dan Gereja Lokal, Jakarta: Bina Kasih, 2011, 26-27.

${ }^{5}$ Audi UI Hakim, https://www.kompasiana.com/audiendro/55006e4fa33311926f5110e3/kepemimpinantransformatif, dalam https://www.kompasiana.com/audiendro, diakses tanggal 16 Maret 2020 jam 14.16 WITA.
} 
masyarakatnya. Pemimpin yang transformatif mengutamakan kepentingan masyarakatnya dari pada kepentingan pribadinya. ${ }^{6}$

Adapun karakteristik pemimpin yang transformatif meliputi: pertama, pemimpin yang transformatif memiliki kharisma. Kedua, pemimpin yang transformatif dapat memotivasi masyarakatnya mengenali berbagai persoalan dan solusi pemecahan masalah. Ketiga, pemimpin yang transformatif memberikan perhatian pada setiap individu dalam masyarakatnya. Keempat, pemimpin yang transformatif memberikan motivasi masyarakatnya dalam mengembangkan ilmu pengetahuan, teknologi dan seni. Kelima, pemimpin yang transformatif berupaya meningkatkan kapasitas para pengikutnya agar bisa mandiri. Keenam, para pemimpin yang transformatif selalu hadir sebagai teladan. $^{7}$

Kepemimpinan yang transformatif juga menjadi karakteristik dalam prototipe kepemimpinan kristiani maupun Pendidikan Agama Kristen (yang selanjutnya disingkat PAK). Karakteristik itu dapat dilihat dalam berbagai pemberitaan Firman Allah dalam Alkitab. Alkitab menyaksikan bahwa sejak dahulu PAK yang dilakukan oleh Yesus Kristus Sang Guru Agung telah mengedepankan karakteristik kepemimpinan yang transformatif. Kristus pertama-tama adalah pemimpin bagi setiap pemimpin pelayan. Artinya, Kristus pertama-tama adalah pemimpin yang memanggil setiap pemimpin-pelayan di dunia ini. ${ }^{8}$

Dalam pemberitaan injil Yohanes menyebutkan bahwa seorang gembala ("pemimpin") memimpin karena ia berada di depan. Ia pergi ke suatu tempat, sehingga ia harus berjalan di depan untuk menunjukkan jalannya. Domba-domba pun hanya mengikuti "pemimpin" gembala mereka. ${ }^{9}$

Dalam pemberitaan Alkitab juga dikisahkan berbagai kesenjangan antara Yesus dan para pemimpin daerah. Di mana Yesus menampakkan kekecewaannya terhadap implementasi kepemimpinan mereka yang lebih banyak merugikan cluster masyarakat kecil demi kepentingan kekuasaan, kekayaan dan kejayaan pemerintahan mereka. Cara Yesus dengan mengaktualisasikan pola kepemimpinan sebagai hamba.

Namun, di sisi lain Yesus juga mengajarkan orang banyak agar tetap menghargai para pemimpin mereka di mana pun mereka berada. Karena para pemimpin sesunggunhnya adalah orang yang diurapi Tuhan. Hanya terkadang para pemimpin lupa akan jatidiri mereka yang sesungguhnya.

Bagaimana dengan konteks kepemimpinan di Indonesia saat ini? Realitanya saat ini, ada beberapa pemimpin yang kurang memahami posisinya sebagai pemimpin. Jabatan pemimpin seringkali dianggap jabatan fundamental yang dapat menguasai banyak hal. Dengan menjadi pemimpin, orang dapat menguasai banyak hal dan dapat berbuat apa saja. Pemikiran yang keliru ini menjadikannya menyalahgunakan jabatan kepemimpinan yang dipercayakan kepadanya. Penyalahgunaan jabatan kepemimpinan yaitu munculnya berbagai contoh keterlibatan pemimpin dalam kasus-kasus pidana. Misalnya: dalam kasus pidana korupsi seperti yang dilansir dalam beberapa pemberitaan tentang kasus DAK Lampung tengah yang menyeret keterlibatan anggota DPR, kasus Suap Proyek Jalan yang melibatkan pejabat Kementerian PUPR, dan lain-lain. ${ }^{10}$ Selain itu ada juga kasus Korupsi NTT Fair yang melibatkan mantan Kepala Dinas PRKP NTT. ${ }^{11}$ Dan masih banyak contoh kasus lainnya.

\footnotetext{
${ }^{6}$ Ibid.

${ }^{7}$ Ibid

${ }^{8}$ S. M. Hutagalung, Identitas Kepemimpinan Pelayanan Gereja, Jakarta: BPK Gunung Mulia, 1988, 6.

${ }^{9}$ Bob Moffitt dan Karla Tesch, Andaikan Yesus..., 26-27.

${ }^{10}$ SINDONEWS.com, https://nasional.sindonews.com/topic/392/korupsi-pejabat, dalam https://www.sindonews.com/, diakses tanggal 16 Maret 2020 jam 14.24 WITA.

${ }^{11}$ Medcom.id, https://www.medcom.id/nasional/daerah/yNL7G4qK-korupsi-ntt-fair-berpotensi-seret-tersangka-

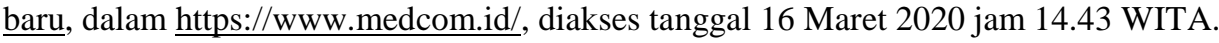


Kepemimpinan di atas adalah tipe kepemimpinan yang mengutamakan kepentingan sepihak dan kekuasaan. Kepemimpinan tipe ini bukanlah kepemimpinan yang mengedepan kepentingan orang-orang yang dipimpinnya. Kepemimpinan ini tidak mendatangkan damai sejahtera bagi masyarakatnya. Bahkan kepemimpinan ini biasanya tidak bertahan lama karena kehilangan kepercayaan dari masyarakatnya. Oleh sebab itu, rumusan masalah yang menjadi fokus pada penelitian ini adalah 1).Apa sesungguhnya kepemimpinan transformatif dari persfektif Pendidikan Agama Kristen? 2). Bagaimana karakteristik kepemimpinan transformatif dalam persfektif Pendidikan Agama Kristen? dan 3). Bagaimana strategi dalam mengimplementasikan kepemimpinan transformatif dalam persfektif Pendidikan Agama Kristen?

\section{METODE PENELITIAN}

Metode penelitian yang digunakan dalam penelitian ini adalah metode deskriptif kualitatif yang membahas secara deskritif kualitatif. Untuk memperoleh data sesuai dengan tujuan penelitian, maka penulis menggunakan teknik pengumpulan yaitu: observasi yaitu pengamatan awal; wawancara dengan menyiapkan daftar pertanyaan wawancara yang sesuai dengan perumusan masalah penelitian. Teknik analisis data adalah dengan mengolah data melalui teknik deskripsi kualitatif dengan menggambarkan atau mendeskripsikan fakta-fakta yang ada di lapangan, kemudian menganalisisnya secara kualitatif.

\section{HASIL DAN ANALISIS}

Adapun hasil penelitian ini menghasilkan analisis sebagai berikut:

\subsection{Kepemimpinan Transformatif}

Apa itu kepemimpinan? Wheatley dalam salah satu tulisannya mengatakan:

Those who help us center our work in a deeper purpose are leaders we cherish, and to whom we return love, gift for gift. ${ }^{12}$

Wheatley mengungkapkan bahwa sosok yang memiliki kewibawaan sehingga layak dihargai dan diberikan apresiasi. Pemimpin yang demikian membawa dampak cinta kasih dalam suatu relasi kebersamaan.

Selain itu, Kotter mengatakan bahwa:

I'm talking about leadershipas the development of vision and strategies, the alignment of relevant people behind those strategies, and the empowerment of individuals to make the vision happen, despite obstacles. This stands in stark contrast with management, which involves keeping the current system operating through planning, budgeting, organizing, staffing, controlling, and problem-solving. Leadership works through people and culture. It's soft and hot. Management works through hierarchy and systems. It's harder and cooler. ${ }^{13}$

Kotter mau menekankan bahwa seseorang disebut pemimpin apabila ia memiliki visi dan strategi yang jelas. Dan selanjutnya, visi dan strategi itu dapat diwujudnyatakan dalam dengan melibatkan sistem kerja yang jelas.

Hal yang sama diungkapkan oleh Bennis yang mengatakan:

12 Douglas B. Reeves, The Daily Disciplines of Leadership- How to Improve Student Achievement, Staff Motivation, and Personal Organization, 9.

${ }^{13}$ Ibid., 10 
Leaders manage the dream. All leaders have the capacity to create a compelling vision, one that takes people to a new place, and the ability to translate that vision into reality. ${ }^{14}$

Ficere dan Fulmer mengatakan:

We believe that, above all else, strategic leaders must have a sense of vision, an ability to set broad, lofty goals and steer a course toward them, but with the insight and flexibility to adjust both the course and the goals asthehorizon becomes clearer. They must be able to communicate the goals and the course to well-educated, technically skilled colleagues. And they must develop the internal and external alliances and supporting communication and reward structures that will ensure the appropriate resources are brought to bear on achieving the organization's strategic objective. ${ }^{15}$

Ficere dan Fulmer menekankan bahwa seorang pemimpin harus memiliki kemampuan mengembangkan visinya. Kemampuan itu harus dikembangkan secara internal dan eksternal. Kemampuan ini akan mendukung komunikasi dalam mencapai tujuan dan statregi yang telah ditetapkan.

Pemimpin hadir ditengah masyarakatnya karena ada harapan dari masyarakat yaitu untuk mencapai suatu tujuan tertentu. Karena itu, masyarakat yang memilih pemimpin mengharapkan fungsi kepemimpinan seorang pemimpin dijalankan dengan tepat untuk mencapai tujuan tersebut. Shtogren mengatakan bahwa:

The function of leadership is to cope with change. Leadership did not have any real meaning in the marketplace until recently, when radical change became the norm. . . . To lead change, skills are needed for creating an attractive vision of the future and making it a real possibility. The test of good leadership is the achievement of intended change in systems and people. ${ }^{16}$ Artinya bahwa keberadaan seorang pemimpin berfungsi untuk tujuan perubahan. Dalam menggapai perubahan, maka dibutuhkan kreatifitas seorang pemimpin dalam mewujudnyatakan visi kepemimpinannya.

Selanjutnya, apa itu kepemimpinan transformatif? Kepemimpinan transformatif adalah kepemimpinan yang diharapkan oleh seluruh masyarakat, baik dalam ranah pemerintahan, politik, pendidikan, agama, ekonomi, dan sebagainya. Kepemimpinan transformatif diidentifikasikan sebagai kepemimpinan dimana para pemimpin menggunakan kharisma mereka untuk melakukan transformasi dan merevitalisasi organisasinya. ${ }^{17}$

Pemimpin yang transformatif biasanya lebih mengutamakan revitalisasi masyarakat dan organisasinya secara intergral dari pada memberikan instruksi yang bersifat topdown. Pemimpin yang transformatif selalu menempatkan diri sebagai mentor yang bersedia menampung aspirasi masyarakatnya. Pemimpin yang transformatif mengutamakan kepentingan masyarakatnya dari pada kepentingan pribadinya. ${ }^{18}$

Adapun karakteristik pemimpin yang transformatif meliputi: pertama, pemimpin yang transformatif memiliki kharisma. Kedua, pemimpin yang transformatif dapat memotivasi masyarakatnya mengenali berbagai persoalan dan solusi pemecahan masalah. Ketiga, pemimpin yang transformatif memberikan perhatian pada setiap individu dalam masyarakatnya. Keempat, pemimpin yang transformatif memberikan motivasi masyarakatnya dalam mengembangkan ilmu pengetahuan, teknologi dan seni. Kelima, pemimpin yang transformatif berupaya meningkatkan kapasitas para

\footnotetext{
${ }^{14}$ Ibid.

${ }^{15}$ Ibid. 10.

${ }^{16}$ Ibid. 11

${ }^{17}$ Audi UI Hakim, https://www.kompasiana.com/audiendro/55006e4fa33311926f5110e3/kepemimpinantransformatif, dalam https://www.kompasiana.com/audiendro, diakses tanggal 16 Maret 2020 jam 14.16 WITA.

${ }^{18}$ Ibid Audi UI Hakim
} 
pengikutnya agar bisa mandiri. Keenam, para pemimpin yang transformatif selalu hadir sebagai teladan. ${ }^{19}$

Berdasarkan uraian tersebut, maka dapat disimpulkan bahwa kepemimpinan transformatif adalah kepemimpinan dimana pemimpinnya memiliki kewibawaan. Dengan kewibawaan, maka pemimpin dapat menjalankan kepemimpinan dengan perencanaan dan strategi yang matang di atas visi dan misi yang jelas dan tepat sasaran. Hal ini akan memberikan peluang bagi pemimpin untuk bersama masyarakatnya menyelesaikan masalah yang dihadapi. Pemimpin yang demikian tentunya memiliki kompetensi untuk mengetahui setiap individu yang dipimpinya. Pemimpin yang demikian adalah pemimpin yang mampu memandang masa depan masyarakatnya, kendala dan tantangan dan dihadapi serta strategi dan peluang apa yang perlu diterapkan untuk menyelaikan tantangan. Pemimpin ini adalah pemimpin yang menghendaki masyarakatnya dapat berkembang secara mandiri. Dan yang paling utama pemimpin ini adalah pemimpin yang mampu menjadi teladan bagi masyarakatnya.

\subsection{Kepemimpinan Transformatif Dalam Perspektif Pendidikan Agama Kristen}

Implementasi Kepemimpinan Transformatif dalam Perspektif PAK dapat dilihat dalam pengalaman Yesus Kristus Sang Guru Agung. Yesus Kristus menerapkan pola kepemimpinan yang transformatif bagi komunitasnya saat itu dan juga masih berlaku bagi orang Kristen saat ini maupun yang akan datang. Karakteristik pola kepemimpinan Yesus ini terutama disaksikan oleh pemberitaan injil sebagai sosok pemimpin yang transformatif.

Pola kepemimpinan Yesus yang transformatif merupakan inti pengajaran dalam Pendidikan Agama Kristen. Pendidikan Agama Kristen sendiri adalah pendidikan berpangkal pada persekutuan umat Tuhan. Dalam Perjanjian Lama pada hakekatnya dasar-dasar terdapat pada sejarah suci purbakala, bahwa Pendidikan Agama Kristen itu mulai sejak terpanggilnya Abraham menjadi nenek moyang umat pilihan Tuhan, bahkan bertumpu pada Allah sendiri karena Allah menjadi peserta didik bagi umat-Nya. ${ }^{20}$ Allah sendiri berkarya dalam diri Yesus Kristus untuk menyatakan karya-Nya bagi dunia, baik dalam zaman Perjanjian Baru maupun pada masa kini dalam karya Roh Kudus.

\subsection{Pemimpin dalam PAK "Pemimpin yang Berwibawa"}

PAK mengajarkan bahwa menjadi pemimpin bukanlah orang yang mencari panggung kekuasaan atau kewenangan. Dalam tulisannya Williamson mengatakan:

Tuhan sendiri tidak pernah menyatakan diri-Nya sebagai Tuhan dengan memaksakan hak-hak prerogatif-Nya sebagai Tuhan. Paulus menyaksikan dalam suratnya kepada Jemaat di Filipi bahwa Allah memasrakan Diri, menyerah, mengosongkan diri dari hak-hak prerogatif-Nya dan menjalani hidup sebagai seorang pelayan. Dia hidup di antara manusia sebagai seseorang yang tidak mengklaim apa-apa untuk Diri-Nya. ${ }^{21}$

Williamson menunjukkan bahwa menjadi pemimpin dalam sudut pandang PAK tidak harus diproklamirkan untuk mendapatkan pengakuan masyarakat. Pemimpin sejatinya mendapat pengakuan dari masyarakat karena kapabilitasnya. Kapabilitas tidak sebatas memiliki skill namun memiliki kompetensi secara mendalam mengenai suatu hal dan mampu mensolusi setiap persoalan. Di sinilah letak kharisma seorang pemimpin yakni kewibawaannya. Banyak orang dapat menjadi pemimpin

\footnotetext{
${ }^{19}$ Ibid Audi UI Hakim,

${ }^{20}$ E.G.Homrighausen dan I. H. Enklaar, Pendidikan Agama Kristen, Jakarta: BPK Gunung Mulia, $2005,12$.

${ }^{21}$ Joseph Williamson, "Pendidikan dari Sudut Pandang Orang Kristen," dalam Bunga Rampai Tulisan tentang Pendidikan Kristen, 2011, 1.
} 
tetapi belum tentu memiliki wibawa. Wibawa itu adalah kharisma. Dan menjadi seorang pemimpin harus memiliki wibawa.

Menariknya pada zaman sekarang, banyak pemimpin mencari panggung kekuasaan, sehingga karakteristiknya sebagai figur pemimpin yang dihormati cenderung pudar. Kewibaawan pemimpin menjadi pudar karena kekuasaan sepihak. Kekuasaan ini biasanya menunjukkan pada pengaruh orang yang berkuasa untuk mendapatkan apa yang diinginkannya. Bentuk yang paling mudah digunakan adalah kekuasaan yang menghancurkan orang lain. Ada orang yang menggunakan kekuasaan untuk mempertahankan diri dan mengancam orang lain. Kekuasaan yang demikian adalah kekuasaan yang bersifat negatif. ${ }^{22}$

Dalam Kekristenan, Yesus Kristus adalah figur pemimpin yang patut menjadi teladan seorang pemimpin yang berwibawa. Ada beberapa hal mengenai kewibawaan Yesus yang perlu diperhatikan.

Pertama, ketika berkarya di dunia, Yesus tidak pernah berhenti memberikan pengajaran kepada orang banyak. Yesus memberikan pengajaran setiap saat, di mana saja dan kapan saja. Yesus mengajar semua kalangan baik orang biasa maupun para elit politik dan agama. Yesus hanya tersenyum dan selalu menguatkan iman mereka baik ketika mereka memberikan rasa kagum maupun ketika mereka menghujat-Nya. Yesus tidak pernah menyerah untuk melakukan pengajaran.

Kedua, Yesus tidak hanya asal mengajar, melainkan juga melakukan tindakan yang nyata atas pengajaran-Nya dengan menyembuhkan orang sakit dan menghibur orang yang berduka. Berita injil terus menyampaikan karya Yesus yang cukup banyak dalam melakukan apa yang kemudian disebut orang banyak "mujizat." Sesungguhnya mujizat yang dimaksudkan mereka adalah apa yang dihayati Yesus sebagai keberpihakan kepada mereka yang termarginal. Yesus selalu berada di depan untuk kalangan rakyat biasa bahkan untuk kalangan yang keberadaannya didiskriminasi.

Ketiga, Yesus lebih mengutamakan kepentingan kemanusiaan rakyat dibandingkan rutinitas ibadah yang cenderung hanya formalitas segelitir orang yang mempolitisasi agama. Injil juga menyaksikan bagaimana Yesus menyembuhkan orang yang lumpuh ketika ibadah berlangsung. Padahal dalam tradisi Yahudi, sikap Yesus adalah sebuah pelanggaran aturan agama yaitu pelanggaran hukum Tuhan yang ke empat dengan tuduhan menista kekudusan hari Sabat. Namun bagi Yesus, keberadaan-Nya di tengah masyarakat adalah untuk mengutamakan kepentingan mereka yang paling urgen, bukan untuk prestise agama yang dipolitisasi.

Hal-hal di atas menunjukkan bahwa Yesus adalah sosok pemimpin yang transformatif. Yesus mentransformasi pemikiran dan pola sikap seorang pemimpin terhadap orang-orang yang dipimpin lebih manusiawi. Karena sikap itulah, Yesus mendapat pengakuan dari orang-orang yang menyaksikan karya hidup-Nya. Injil Markus 15:39 menyaksikan: "Waktu kepala pasukan yang berdiri berhadapan dengan Dia melihat mati-Nya demikian, berkatalah ia: Sungguh, orang ini adalah Anak Allah.”

Alkitab menyaksikan bahwa pengakuan akan kewibawaan Yesus bukan berasal dari ungkapan verbal Yesus. Pengakuan akan kewibawaan Yesus hadir melalui tindakan dan sikap hidup Yesus yang memberikan pengaruh positif bagi orang lain.

Kepemimpinan transfomatif dalam sudut pandang PAK memberikan interpretasi baru bagi setiap pemimpin di Indonesia. Nilai-nilai karakteristik PAK yang menjadi strategi dalam mengimplementasikan kepemimpinan transformatif adalah bahwa menjadi pemimpin sejatinya datang dari pengakuan akan kapabilitas diri. Pemimpin dengan kapabilitas diri adalah pemimpin yang memiliki kewibawaan. Kewibawaan seorang pemimpin memberikan pengaruh positif di tengah masyarakat yang dipimpinnya. Pengaruh positif itu memotivasi pemimpin tidak hanya mengucapkan

${ }^{22}$ G. Therik, "Kekuatan Cinta-The Power of Lover: Wajah Kekuasaan dalam Gereja," dalam Journal Teologi Sosial, Kupang: UKAW, 2004, 33. 
kata-kata yang hampa, melainkan melakukan tindakan nyata. Pengaruh positif itu juga mengutamakan kepentingan masyarakat dari pada kepentingan pribadi, sehingga masyarakat mampu menyelesaikan setiap persoalan yang dihadapi. Selain itu, pengaruh positif juga menciptakan ikatan emosional yang kuat antara pemimpin dan masyarakatnya, sehingga semua persoalan diselesaikan secara bersamasama.

\subsection{Pemimpin dalam PAK sebagai "Figure who Resolves the Problem"}

PAK mengajarkan bahwa seorang pemimpin mampu menjadi sosok yang memecahkan masalah bersama masyarakatnya. Kusumahadhi dalam tulisannya mengatakan bahwa:

Kesadaran akan tanggungjawab itu menolong para pemimpin untuk melihat diri bukan sebagai masyarakat kelas atas. Tetapi mereka melihat diri sebagai bagian dari masyarakat sosial yang berhak dilayani. Dalam hal ini menolong masyarakat sosial rendah memiliki semangat menjalankan aktivitas hidupnya serta menemukan makna dalam pekerjaan dan tanggungjawabnya. ${ }^{23}$

Kusumahadhi memaparkan bahwa pemimpin harus menempatkan diri dalam konteks masyarakat yang dipimpinnya. Para pemimpin yang selalu ada bersama masyarakat akan memotivasi mereka untuk menjalani hidup dengan penuh semangat dan tanggungjawab.

Pada zaman saat ini harus diakui bahwa ada pemimpin yang tidak pandai menempatkan diri di tengah konteks masyarakatnya. Pemimpin justru mengukur kemampuan masyarakat dari sudut pandang dirinya, sehingga menilai masyarakatnya yang kurang berkompetensi. Konsekwensinya pemimpin dan masyarakatnya tidak ada kesepemahaman dalam kata dan tindakan. Pemimpin membuat berbagai aturan, sedangkan masyarakat mengacuhkan aturan. Pemimpin tidak mampu mensolusi persoalan, melainkan menambah persoalan.

Yesus adalah pemimpin transformatif yang selalu menempatkan diri di tengah masyarakat. Karena itu, dalam kata dan tindakan-Nya selalu ada solusi bagi mereka. Orang-orang yang mengikutiNya mendengarkan pengajaran-Nya, kemudian juga disembuhkan dari sakit dan dihibur ketika berduka. Ada beberapa karakteristik berkaitan dengan sikap Yesus yang selalu ada di tengah masyarakat.

Pertama, Yesus mendengarkan keluhan orang. Ketika hendak memberikan pengajaran, Yesus selalu mendengar keluhan dan masalah orang yang mengikuti-Nya. Yesus mendengarkan dengan seksama tanpa membantah keluhan mereka. Mendengar adalah salah satu sikap kepedulian Yesus terhadap mereka.

Kedua, Yesus terharu dengan keluhan orang. Ketika mendengar Yesus sering menunjukkan sikap terharu bahkan dalam beberapa peristiwa Ia menangis bersama mereka. Hal ini menunjukkan rasa empati-Nya yang besar terhadap mereka. Sesungguhnya Yesus berupaya menempatkan diri seperti yang dialami mereka. Dengan demikian, Yesus merasakan apa yang dirasakan mereka.

Ketiga, Yesus menasihati orang. Yesus tidak hanya berempati, tetapi juga menasihati orang yang mengikuti-Nya. Nasihat menjadi hal yang menenangkan jiwa mereka. Yesus memotivasi mereka bahwa setiap masalah selalu ada solusi.

Keempat, Yesus bertindak menyelesaikan keluhan orang. Setelah menasihati dengan pengajaran-Nya, biasanya Yesus melakukan sebuah tindakan. Misalnya menyembuhkan orang sakit dan menghibur orang yang berduka. Yesus tidak hanya berkata-kata tetapi juga bertindak.

${ }^{23}$ M. Kusumahadhi, “Tentang Kepemimpinan,” dalam Kepemimpinan Visioner bagi Organisasi Kepemimpinan Masyarakat Sipil, Yogyakarta: SATUNAMA, 2004, 3. 
Kelima, Yesus menguatkan iman orang. Pada akhirnya, Yesus selalu menguatkan iman mereka. Yesus selalu berkata: bangkitlah dan percayalah, pergilah dalam iman, imanmu menyelamatkan, dan lain-lain.

Hal di atas menunjukkan bahwa pemimpin dalam PAK adalah sosok yang harus dapat menyelesaikan masalah. Strategi pemimpin yang transformative adalah mampu menyelesaikan masalah dengan selalu hadir di tengah-tengah masyarakat. Kehadiran pemimpin di tengah masyarakat diaktualisasikan melalui sikap pemimpin yang mendengarkan keluhan masyarakat, berempati dan menasihati masyarakat, bertindak untuk kepentingan masyarakat dan menguatkan kepercayaan diri masyarakat.

\subsection{Pemimpin dalam PAK "Pemimpin yang Mengenal setiap Individu"}

PAK mengajarkan bahwa setiap pemimpin harus mengenal setiap individu yang dipimpinnya. Pemimpin yang transformatif memberikan perhatian pada setiap individu dalam masyarakatnya. Perhatian yang diberikan kepada setiap individu tentunya akan mengokohkan ikatan emosional antara pemimpin dan masyarakatnya secara individu. Selain itu dampaknya secara transformatif memotivasi skill individu. Bridges dan Mitchell dalam tulisannya mengatakan:

Jenis kepemimpinan yang paling efektif saat ini sama dengan jenis jasa yang diberikan konsultan terbaik untuk kliennya; bantuan kolaboratif yang bersifat pemecahan masalah dan pengembangan. Targetnya adalah situasi sekaligus kemampuan profesional seseorang. ${ }^{24}$

Bridges dan Mitchell mengungkapkan bahwa para pemimpin adalah para konsultan yang memberikan solusi pada kliennya. Dalam proses ini, seorang konsultan tentunya harus mengetahui secara detail tentang kliennya. Sehingga ia dapat menolong kliennya menemukan solusi terbaik bagi masalahnya.

Yesus Kristus adalah pemimpin transformatif yang mengenal setiap individu yang mengikutiNya. Yesus menggambarkan Diri-Nya sebagai gembala yang baik yang mengenal domba-domba-Nya dan domba-domba mengenal-Nya (Yohanes 10:14). Ada beberapa karakteristik Yesus mengenal individu setiap orang yang mengikuti-Nya.

Pertama, Yesus mengenal setiap kepribadian mereka. Artinya, Yesus mengetahui sifat dan sikap mereka. Yesus peka terhadap setiap karakter mereka. Karena itu, ketika hendak memberikan mereka pengajaran dan melakukan sebuah tindakan nyata, Yesus menggunakan pendekatan karakter mereka yang dikolaborasikan dengan konteks di mana mereka berada. Misalnya: mereka adalah nelayan maka konteks pengajaran-Nya menggunakan karakteristik seorang nelayan. Mereka adalah gembala, maka konteks pengajaran-Nya menggunakan karakteristik seorang gembala. Dan masih banyak contoh lainnya.

Kedua, karena sikapnya itu, maka Yesus pun dikenal sebagai pemimpin yang berwibawa oleh orang yang mengikuti-Nya. Penerimaan orang banyak pada keberadaan Yesus memberikan ruang lingkup bagi aktualisasi pengajaran Yesus.

Hal diatas menunjukkan bahwa strategi seorang pemimpin transformatif dalam PAK adalah mengenal secara detail karakteristik individual masyarakatnya. Bahkan memberikan pengalaman timbal balik di mana masyarakat juga mengenal secara detail karakteristik pemimpinnya. Pengalaman saling mengenal membawa dampak positif bagi relasi interaksi yang kondusif antara pemimpin dan masyarakatnya.

\subsection{Pemimpin Dalam PAK “Pemimpin Yang Memandang Masa Depan”}

\footnotetext{
${ }^{24}$ W. Bridges dan S. Mitchell, "Memimpin Transisi: Model untuk Perubahan," dalam On Leading ChangeStrategi Menembus Perubahan, Editor: F. Heselbein dan R. Johnston, Jakarta: Elex Media Komputindo Kelompok Gramedia, 2005, 51.
} 
PAK mengajarkan bahwa pemimpin transformatif harus menjadi pemimpin yang mampu memandang masa depan. Pemimpin yang mampu memandang masa depan berarti peka terhadap berbagai perkembangan dan inovasi dalam kehidupan masyarakatnya. Marshall dalam tulisannya mengatakan:

Yang membedakan pemimpin dari orang-orang lain adalah mereka bukan hanya berminat pada masa depan, namun juga memiliki kemampuan untuk menanggapinya. Kemampuan itu disebut tinjauan ke masa depan. ${ }^{25}$

Pendapat Marshall mau menunjukkan bahwa dalam kepemimpinan transformatif, maka seorang pemimpin tidak hanya berminat pada masa depan, melainkan menanggapi masa depan. Menangggapi berarti peka terhadap berbagai perkembangan dan transformasi yang akan terjadi di masa depan. Hal ini mengindikasikan bahwa visi, misi, tujuan, sasaran serta strategi yang dikembangkan oleh seorang pemimpin harus mempertimbangkan kepentingan masyarakat untuk masa depan.

Yesus Kristus adalah sosok pemimpin transformatif yang memandang masa depan orangorang yang mengikuti-Nya. Ada beberapa karakteristik yang menunjukkan kepekaan Yesus pada masa depan.

Pertama, orientasi pikiran Yesus yang tertuju pada masa depan. Jika hendak menemukan sesuatu maka harus terus mencari. Kata Yesus: Carilah maka kamu akan mendapatinya (Matius 7:7).

Kedua, Yesus mengimplementasikan ide-ide baru dengan banyak belajar dari pembelajaran dan pengalaman di masa lalu. Misalnya ketika Ia ditantang untuk menghakimi perempuan yang berdosa. Ia merekonstruksi secara baru pembelajaran dan pengalaman Taurat Musa di masa lalu dan disesuaikan dengan konteks masa kini. Inspirasi kreatif Yesus muncul dalam kalimat: "Barangsiapa di antara kamu yang tidak berdosa, hendaklah ia yang pertama melemparkan batu pada perempuan itu." (Yohanes 8:7).

Hal di atas menunjukkan bahwa pemimpin transformatif adalah pemimpin yang selalu memandang ke masa depan. Pemimpin harus berupaya menemukan sesuatu yang baru di masa depan. Namun, pemimpin juga harus berani menampilkan ide-ide baru serta siap menghadapi resiko yang ada.

\subsection{Pemimpin Dalam PAK "Menjadikan Orang Yang Dipimpin Mandiri”}

PAK mengajarkan seorang pemimpin yang transformatif menjadi sosok yang berupaya meningkatkan kapasitas para pengikutnya agar bisa mandiri. Dalam tulisannya lebih lanjut, Bridges dan Mitchell mengatakan:

Yesus memberdayakan para murid-Nya. Keberpihakan Yesus pada realitas nampak dalam pemberdayaan-Nya terhadap orang-orang yang dipimpin-Nya. ${ }^{26}$

Pendapat Bridges dan Mitchell menunjukkan bahwa Yesus menginginkan orang yang mengikuti-Nya pada akhirnya menjadi orang yang mandiri. Mandiri dalam tindakan kasih dan iman.

Yesus adalah pemimpin transformatif yang menjadikan orang-orang yang mengikuti-Nya mandiri. Ada beberapa karakteristik Yesus yang menjadikan orang-orang yang mengikuti-Nya dapat berkembang secara mandiri.

Pertama, Yesus menginginkan orang mandiri dalam bertindak. Ketika Ia menyembuhkan orang lumpuh, Ia mengatakan: bangunlah dan berjalanlah. Bahwa persoalan yang dihadapi setiap orang pertama-tama harus disikapi secara mandiri oleh orang tersebut. Pertolongan orang lain adalah

\footnotetext{
${ }^{25}$ Tom Marshall, Pemimpin Efektif-Belajar Memahami Pola Kepemimpinan di dalam Perjanjian Baru, Jakarta: Metanoia, 1996, 3.

${ }^{26}$ Bridges dan Mitchell, Memimpin Transisi..., 40.
} 
suatu konsekwensi solidaritas dalam sebuah kebersamaan, tetapi motivasi perubahan atau solusi terhadap masalah harus lahir dari kemandirian tindakan orang tersebut.

Kedua, Yesus menginginkan orang mandiri dalam keyakinan. Setiap orang memiliki keyakinan dan kepercayaan yang lahir secara mandiri dari orang tersebut. Dukungan orang lain adalah untuk meneguhkan keyakinan yang sesungguhnya harus lahir dari pribadi secara mandiri.

Hal di atas menunjukkan bahwa strategi pemimpin transformatif dalam PAK adalah mampu memimpin masyarakatnya menjadi masyarakat yang mandiri. Mandiri dalam tindakan dan mandiri dalam keyakinan.

\subsection{Pemimpin Dalam PAK "Pemimpin Sebagai Teladan"}

PAK mengajarkan bahwa seorang pemimpin yang transformatif adalah pemimpin yang selalu hadir sebagai teladan. Tomatola dalam tulisannya mengatakan:

Salah satu faktor yang dibutuhkan dunia saat ini adalah kebutuhan akan pemimpin yang patut diteladani dan dicontohi kehidupannya, terutama dalam hubungan dengan orang lain. Namun untuk menemukan para pemimpin yang demikian semakin sulit. ${ }^{27}$

Tomatola hendak mengungkap bahwa dunia sangat membutuhkan pemimpin yang diteladani dalam sikap dan karakteristiknya. Namun saat ini sulit menemukan pemimpin yang demikian.

Yesus adalah pemimpin transformatif yang selalu menjadi teladan bagi orang yang mengikutiNya. Apa saja yang dilakukan-Nya ditinggalkan sebagai teladan. Karakteristik sikap keteladanan Yesus dapat dilihat dalam beberapa hal.

Pertama, Yesus penuh kasih. Ia menyatakan kasih-Nya kepada orang yang mengikutinya dan menghendaki mereka juga melakukan kasih bagi sesama. Yesus menggenapi penyataan hukum Taurat yaitu kasih kepada Allah dan kasih kepada sesama.

Kedua, Yesus memiliki sikap rendah hati. Ia tidak menunjukkan diri sebagai yang berkuasa seperti pemikiran manusia, melainkan mengambil rupa seorang hamba dan melayani manusia dengan tulus. Yesus menghendaki setiap orang memiliki sikap yang rendah hati.

Hal tersebut menunjukkan bahwa strategi pemimpin yang transformatif dalam PAK adalah harus menjadi teladan. Pemimpin harus menjadi teladan kasih dan kerendahan hati bagi sesamanya.

\section{PENUTUP}

Kepemimpinan adalah sebuah karakteristik penting bagi seorang pemimpin. Pemimpin dengan visi dan misi membawa kesejahteraan bagi orang-orang yang dipimpinnya haruslah pemimpin yang memiliki kepemimpinan yang tepat. Dan salah satu karakteristik kepemimpinan yang penting saat ini adalah kepemimpinan transformatif. Sedangkan kepemimpinan transformasi dalam perspektif Pendidikan Agama Kristen dapat dilihat dalam karakter kepemimpinan Yesus. Kepemimpinan transformatif Yesus ini menunjukkan bahwa dalam kepemimpinan, seorang pemimpin harus memiliki kewibawaan. Dengan kewibawaan, maka pemimpin dapat menjalankan kepemimpinan dengan perencanaan dan strategi yang matang di atas visi dan misi yang jelas dan tepat sasaran. Pemimpin ini adalah pemimpin yang menghendaki masyarakatnya dapat berkembang secara mandiri. Dan yang paling utama pemimpin ini adalah pemimpin yang mampu menjadi teladan bagi masyarakatnya.

\footnotetext{
${ }^{27}$ Y. Tomatola, Kepemimpinan yang Dinamis, Malang: Gandum, 1997, 55.
} 


\section{DAFTAR PUSTAKA}

\section{Buku}

Bridges, W. dan Mitchell, S., 2005, "Memimpin Transisi: Model untuk Perubahan." dalam On Leading Change-Strategi Menembus Perubahan. Editor: F. Heselbein dan R. Johnston. Jakarta: Elex Media Komputindo Kelompok Gramedia.

Homrighausen, E.G. dan Enklaar, I. H., 2015. Pendidikan Agama Kristen. Jakarta: BPK Gunung Mulia.

Hutagalung, S. M., 1988, Identitas Kepemimpinan Pelayanan Gereja. Jakarta: BPK Gunung Mulia.

Kusumahadhi, M., 2004. "Tentang Kepemimpinan." dalam Kepemimpinan Visioner bagi Organisasi Kepemimpinan Masyarakat Sipil. Yogyakarta: SATUNAMA.

Lawler, J. 2007. "Leadership in social work: A case of caveat emptor?". British Journal of Social Work, $37,123-41$.

Lunenburg, C. Fred. 2011. Self-Efficacy in the Workplace: Implications for Motivation and Performance. Sam Houstan State University, International Journal Of Management, Business, and Administration. Vol. 14. Number 1, 2011

Marshall, Tom, 1996. Pemimpin Efektif-Belajar Memahami Pola Kepemimpinan di dalam Perjanjian Baru. Jakarta: Metanoia.

Moffitt, Bob dan Tesch, Karla. 2011. Andaikan Yesus Kepala Daerah-Tranformasi dan Gereja Lokal. Jakarta: Bina Kasih.

Pamudji, S., 1989. Kepemimpinan Pemerintahan di Indonesia. Jakarta: Bina Aksara.

Reeves, Douglas B., 1953. The Daily Disciplines of Leadership-How to Improve Student Achievement, Staff Motivation, and Personal Organization, San Franscisco: Jossey-Bass.

Sugiyono, 2017. Metode Penelitian Kuantitatif, Kualitatif, dan Penelitian dan Pengembangan. Jakarta: Alfabet.

Therik, G., 2004. "Kekuatan Cinta-The Power of Lover: Wajah Kekuasaan dalam Gereja." dalam Journal Teologi Sosial. Kupang: UKAW.

Tomatola, Y., 1997. Kepemimpinan yang Dinamis. Malang: Gandum.

Williamson, Joseph, 2011."Pendidikan dari Sudut Pandang Orang Kristen." dalam Bunga Rampai Tulisan tentang Pendidikan Kristen. 


\section{Website}

Audi UI Hakim,

https://www.kompasiana.com/audiendro/55006e4fa33311926f5110e3/kepemimpinantransformatif, dalam https://www.kompasiana.com/audiendro, diakses tanggal 16 Maret 2020 jam 14.16 WITA.

Medcom.id, https://www.medcom.id/nasional/daerah/yNL7G4qK-korupsi-ntt-fair-berpotensi-serettersangka-baru, dalam https://www.medcom.id/, diakses tanggal 16 Maret 2020 jam 14.43 WITA.

SINDONEWS.com, https://nasional.sindonews.com/topic/392/korupsi-pejabat, dalam https://www.sindonews.com/, diakses tanggal 16 Maret 2020 jam 14.24 WITA. 